\title{
QUALITATIVE CONDITIONS OF SCIENTOMETRICS: THE NEW CHALLENGES
}

\author{
A. RIP \\ Centre for Studies on Science, Technology and Society, University of Twente, \\ P.O. Box 217, 7500 AE Enschede (The Netherlands)
}

(Received October 3, 1996)

\begin{abstract}
While scientometrics is now an established field, there are challenges. A closer look at how scientometricians aggregate building blocks into artfully made products, and point-represent these (e.g. as the map of field $\mathrm{X}$ ) allows one to overcome the dependence on judgements of scientists for validation, and replace or complement these with intrinsic validation, based on quality checks of the several steps. Such quality checks require qualitative analysis of the domains being studied. Qualitative analysis is also necessary when noninstitutionalized domains and/or domains which do not emphasize texts are to be studied. A further challenge is to reflect on the effects of scientometrics on the development of science; indicators could lead to 'induced' aggregation. The availability of scientometric tools and insights might allow scientists and science to become more reflexive.
\end{abstract}

\section{Introduction}

What is it that scientometricians do when they study the workings of science with their particular methods? What does quality of their work consist in? These questions are related to the issue of the maturity of scientometrics, as it was taken up recently in the pages of this journal (Note 1), but I will approach this issue in a different way, focussing on what scientometricians actually do and how they create robust results. I shall develop an analysis in terms of building blocks and aggregation of data, an analysis which also allows me to evaluate ongoing discussions about the validity of indicators and other products of the scientometrician's craft.

These discussions, however, are not just about methodology. They are also about the standing, and more generally, the role of the scientometrician. So I will broaden the analysis and locate scientometrics in relation to the evolution of the science system in interaction with science policies. The actual and possible contributions from scientometrics are one input into, and also a component of this interactive system. It is 
only through taking this wider context into account that one can articulate what a mature and reflexive scientometrics would be like.

A basic point is that the quality of the products of the scientometrician depends on the quality of what he or she can draw upon. This concern about the inputs is visible when scientometrics scholars, especially those who produce science indicators, complained about the sloppy way that scientists cite references, or university departments keep up their publication lists. On occasion, scientometricians have suggested that scientists and universities should behave in a more disciplined way because it would make life so much easier for the indicator makers.

Clearly, it is not the first priority of scientists and universities to make the life of scientometricians easier. Scientists do show more discipline in citing and keeping publication lists, but it is for other reasons: because of the strategic games they are involved in. Such games are played among colleagues who are also competitors. University administrators and science policy officials are involved at a distance. Individual scientists or research groups realize that scientometric data and indicators may be used against them, so they make sure they are prepared. If these technical requirements of scientometrics are fulfilled, it is not out of respect for methodology, but because of the nature of the strategic games that are played.

This example indicates that scientometrics is a second-order science, in the sense that scientometricians depend on science and its workings to execute their own craft. The relationship also works in the other direction. The same scientometricians who depend on the working of science and science policy to get the right data, will occasionally argue that their work is also important to have science and science policy working allright. Irvine and Martin's claim that science indicators should be used "to keep peer review honest" is an example (Note 2). Whether one agrees with their position or not, it shows that one can think of a responsibility of scientometrics towards science.

The responsibility is not just between scientometrics and science, but mediated by the link of scientometrics with science administrators and science policy makers (as is clear in Irvine and Martin's defense of their position). Many scientometrics studies are supported by science adminstrators and policy makers, and sometimes performed in such a context. Scientometricians often identify with the issues faced by administrators and science policy makers, rather than with the situation of individual scientists.

Thus, scientometrics activities should be located in a triangle. There are scientometricians, say in the top corner, who study their object, scientists and science. The latter, with their own subjectivity (that is, intentions and strategies), occupy the second corner. The audiences for scientometrics are in the third corner: primarily 
science administrators and policy makers (with their own relation to science and scientists), but sometimes scientists as well.

There are productive interactions, as well as tensions in this "eternal" triangle. In terms of methods and techniques, the field of scientometrics may well be mature, but recognition of the tensions and challenges in the "eternal" triangle should be integrated in the field.

Before I turn to the nature of the work of scientometricians and its location in the triangle, let me note that I have been using the unusual term 'scientometrician' as an easy shorthand - but also because of its resonance with 'magician.' There is magic in the production of indicators, maps, and other scientometric results out of data bases (existing or specially constructed). The scientometrician may turn out to be a magician's pupil: competent to go through the manipulations, but not able to stop the wider processes when there are 'perverse effects.' This is why I insisted on adding reflexivity to the notion of maturity of the field of scientometrics.

\section{The field of scientometrics}

Let me briefly recapitulate the evolution of scientometrics in order to articulate my question what a mature scientometrics could be.

One can distinguish three phases. In the first phase, in the 1960s and early 1970s, data collection and analysis were primary, and scientometricians explored what these data might indicate. In the second phase, claims of scientometricians about their findings led to what I call a struggle about representation: are these data and indicators good representations of scientific developments, scientific quality etc.? With the partial closure of this debate in the late 1980s, the focus shifted to the question of the added value of scientometric studies for various audiences.

In the first phase, scholars like Derek Price were interested in quantitative data about science, which were often laying around without anybody cioing anything much with it. Whether such data were contained in volumes in a library in Malaysia, or in computer tapes laying around, Price did great things with them. Even so, it was a period that should be characterized as one of data (being collected or already available) in search of something to indicate.

Eugene Garfield, starting from library and information science, created a technology to transform scientific literature into databases, and actively pursued ways to convince potential users that these data had some use (up to tables showing that Nobel Prize winners were actually scoring high on citations, suggesting that citation scores would 
have a predictive value - even if, according to his own tables, the hit rate of Nobel Prizes among highly scoring scientists was between 10 and 20\%) (Ref. 3, pp. 80-81).

In the second phase, the data had found "things" they could indicate. Data were transformed into science indicators, and real business started. What scientometricians and/or administrators proposed that these data represented was contested. The "struggle about representation" led to discussions of methodology and validity, but the points made were (also) weapons in a struggle of interests. In the late $1970 \mathrm{~s}$ and the $1980 \mathrm{~s}$, everybody who was actually or potentially threatened by the value of scientometric indicators for his (sometimes her) situation, tried to undermine their validity. Officials who wanted to draw on such data and analysis, faced the risk of losing legitimation with their primary audiences, scientists on the one hand and the government machinery on the other.

It was the latter group, government actors trying to get an overview, which was also interested in the possibilities of mapping techniques, and they had special studies done. Interestingly, the scientists themselves were asked to check the validity of the maps; this happened as much to check the extent of legitimation as that there was an explicit recognition of their expertise (e.g., Ref. 4).

One effect of the arguments, counter-arguments, studies, and also debates in various periodicals, was that the quality of indicators improved, and that understanding of the scope of their applicability spread. Some scientometricians, like Tony van Raan and Ben Martin, now have sufficient status to advise on the basis of their findings; and to ask scientists to behave better to facilitate the construction of indicators.

So has a third and mature phase arrived? There is a third phase, definitely. Representation is becoming less interesting as an issue, and it is the added value of indicators and maps (for various audiences, scholarly and otherwise) what counts. The first challenge is to operationalize validity if representation is not the key anymore, and to articulate what would be added value. In other words, it is necessary to better understand the nature of the achievement of scientometrics. This question will be addressed in Sections 3 and 4.

The second challenge is to understand the conditions of applicability of the achievements. My claim is that one has to look at practices, institutions and their outcomes in science and science organisations and assess how far these are institutionalized, codified and "disciplined." As I will argue in Section 4, and explore further in Section 5, such a qualitative study of science should be part of the craft of the (mature) scientometrician, because validity and applicability of his products depend on the extent of disciplined behaviour in science. 
The third challenge is to reflect on the practice and institutionalisation of scientometrics itself. It is for this purpose that I introduced the "eternal" triangle. It is a simplified scheme, but it has heuristic value. In the discussion of this paper at the NECSTS conference, for example, it led to a consideration of "hidden" actors: publishers and their business strategies, libraries and possible lock-in effects of their rationalization of subscriptions. In Section 6, I discuss one key issue, that of induced aggregation.

It is by meeting these challenges that scientometrics can become really mature.

\section{Scientometrics as second-order aggregation}

It is easy to criticize citation analysis and other scientometric analyses from a sociological point of view (e.g., Ref. 5). The key point, however, is that scientometrics does not just depend on what is actually happening in science (and is therefore a second-order science like other social sciences), but also adds something to it. When Michel Callon, John Law and I had worked on a book on co-word analysis, ${ }^{6}$ we realized only afterwards that we had ventured into the extra-local, with the help of computerized data bases, and constructed things (maps) that actors could not have produced by themselves. If scientometricians construct their products and in this way add to the world, another way of thinking about 'representation' is necessary. I shall use the concept of 'aggregation' to describe what happens.

Aggregation occurs already, "naturally," within science, when scientists elaborate cognitive maps of their research area, think in terms of a research front, write and read review articles. Aggregation occurs also when quality and performance are assessed. Colleagues/competitors learn how to assess research results and function in peer review processes. Institutions have emerged (one example being the awarding of prizes) which honour excellent performance. Garfield's Institute of Scientific Information has tried to link up with these aggregation processes by showing it can produce similar results: maps of research areas, lists of potential Nobel Prize winners.

Scientometrics can tap such institutionalized features of science and by way of second-order aggregation, use the results to build indicators. An exemplary achievement was the way Irvine and Martin, in the early 1980s, used a variety of data, ranging from measures of publications and citations (i.e. outcomes of formal and informal peer review) to structured tapping of peer's judgements in interviews, to support their assessments of big telescope institutes. ${ }^{7}$ 
So what do the Callons, the Garfields, and the Irvines and Martins of this world do when they construct their second-order aggregations? I distinguish three types of activity, three steps in the construction process.

Think of craftsmen building a house, or a construction more generally. They need building blocks rather than raw materials, and put a lot of work in fashioning and polishing the stones they could find in the earth. Similarly, what a scientometrician uses are not raw data, but fashioned and polished data. Think of the hard work involved in "cleaning up your data", and the craft decision when it is enough, depending on the purpose at hand - the Leiden group has argued that $99 \%$ reliability is necessary for performance indicators (to trace overall patterns one could do with less), and that going further would be excessively costly.

With such building blocks a construction is made. I shall use the concept of aggregation to characterize not only what happens overall, but also more specifically to indicate the combinations and translations when building blocks are put together and a transformation to coherence at a higher level is wrought. The house should be a house, not assorted walls, possages and roofs. The construction of scientometric indicators and maps are clear examples of aggregation, and hopefully one leading to higher-level coherence.

The little phrase "the house should be a house" actually includes another point, and this exemplifies the third step in what scientometricians do. By calling a construction 'a house', it is represented in a certain way, and to certain audiences, and expectations can be raised how it will function when used. Post-modern architects can play with such expectations and create post-modern houses in California which do not look like a house. The point is that the craftsman creates what actor-network theorists call a 'point representation': calling this product of his own aggregation work a house is presenting it in a certain way to the world.

Similarly, it is the scientometrician who calls his aggregate 'a map of the field of recombinant DNA research' or 'an indicator of performance of university research groups,' and thus sets in motion the struggle about representation. In the 1970s and 1980 s, the battles were fought in terms of representation-as-mirroring, which seemed natural because the products of the scientometrician's craft are textual, and the content of a descriptive text is, in our modern culture, taken to represent the world outside. Even so, the metaphor of constructing a house teaches us that the question to what extent the map or the indicator stands for what is usually understood as 'this field of science' or 'that scientific performance' is a practical question, not a theoretical one. It is a question whether the construct can, for the purposes at hand, be used in a reliable and profitable way. 
From this brief analysis of the scientometrician's craft as consisting of the creation of building blocks, the aggregation into larger wholes, and their point representation, it follows that there are two ways to validate his work. One is extrinsic: checking the quality of the results as such, by involving scientists as experts, i.e. as persons who know about aggregated representations of science. The other is intrinsic (and professional): specifying and assessing the kind of work that has gone into the creation of the product, and how it relates to the contexts of use of the product.

In both, aggregation processes which occur anyhow, independent of the activities of the scientometrician, are a referent, but in different ways. If we position the scientometrician's work as 'artificial aggregation', to emphasize its artifactual character, both in the sense of the risk of creating artifacts, and in the sense of creating artfully crafted products, extrinsic and intrinsic validation can be distinguished in terms of risks to be avoided. Extrinsic validation by scientists reduces the risk of artifacts, in sofar as these are results not recognized by scientists. Intrinsic validation focusses on the craft that has gone into production of the result, and reduces the risk that the results are not robust.

I shall elaborate intrinsic validation in the next section, and discuss the strengths and weaknesses of extrinsic validation here.

Why would scientists be experts in checking scientometrics results? The basic point is that, with sufficient experience, they have relevant expertise because their "natural" aggregation processes are similar to the ones scientometricians use. Scientists aggregate building blocks into an overall picture, often without reflecting on how they do it. Quality control of such pictures resides in the communication system: partly formally, when further publications (and criticisms of earlier publications) are taken into account, but mostly informally, when scientist $X$ mentions to scientist $Y$ what he thinks of $Z$, or how reliable finding $A$ is; gets a response and finds his assessment reinforced or weakened. Point representations occur as well, for example when scientist $\mathrm{X}$ is required to judge the work of another group, or assess the state of the art. The force of such point representations depends on status of scientist $X$, as well as on the arguments and analysis put forward.

Scientists themselves are concerned about quality, debate it, and argue for or against representations made by other scientists. Thus, the claim is, they should also judge the quality of the products of the scientometrician, or at least have a privileged position in judging the results of second-order aggregation.

While there are good reasons, there are also problems. One is the opaqueness of processes of quality control in science. Peer review may or may not work well, but it is 
difficult to trace its quality. So one does not know whether the scientific judges are actually competent to judge.

Secondly, scientometrics, of necessity, uses building blocks cut out from their original contexts, and can take only a limited number of features into account in its aggregation processes. So scientists can check whether important features have been missed. But again, there are problems. Each scientist has his or her specific views and experiences, while the scientometrician, even when being selective, can build a more cosmopolitan picture. For example, Amsterdamska and Leydesdorff noted: "...there is no reason to assume a priori that the citation network as perceived by the actors involved is the same as the one being established by the aggregate of their acts at the level of the structure of the sciences." (Ref. 8, p. 450). Citing other publications in one's own article is part of the strategic game of transforming the literature so as to push one's own results. Since one has to take into account prevalent views and strength of other results, citing strategies are bound up with the state of the field as well. Thus, a scientist will have some insight into the overall picture, but still look at the field through the lens of his (or her) own situation. The scientometrician, with his or her craft, abstracts from actor strategies and produces an overall picture in its own right.

Thirdly, the advantage of having scientists as final arbiters of the results of scientometrics contributes to their legitimation. Scientometricians are (at least were) not powerful enough to stand up against eventual indignation of scientists (although luckily, there are often differences of opinion, and scientometricians can then find support from other parts of the scientific community). In addition, since scientometric work is often supported by policy makers who cannot proceed without some legitimation from the scientific community, they want results from scientometrics which are acceptable to that scientific community. The problem, of course, is that acceptability need not relate to the quality of the product, but depends on the extent to which the product reinforces received opinions and/or interests.

If representation in the sense of mirroring what scientists know would remain the definitive criterion, this would, in effect, amount to a situation where scientometricians were not telling scientists anything new. (There would still be a function for scientometrics: spying on scientists and report on them to administrators and policy makers (Note 3)). In the second phase of scientometrics, when recognizability to scientists was required, deadlocks resulted, because when recognizability was realized, the response was that scientometricians had nothing new to say. So it is important to turn the tables and argue that results not recognized immediately shows that there is an added value to the work of the scientometrician. This does require some form of intrinsic validation, however (see Section 4). 
There is an interesting comparison with anthropologists to be made. Anthropologists circulate among their subjects on a Pacific island or in the poor quarters of an American city, but deliver their stories to academic audiences. This is possible also because of status and power gradients. Scientometricians can also limit themselves to presenting their products in their own circles (and jargon helps to make their stories inaccessible to others). But their subjects, scientists, are present in the same society as the scientometricians and their sponsors, and are often quite powerful. So scientometricians cannot hide from their subjects.

If they cannot hide from their subjects, they are also exposed to their recriminations (Note 4). An interesting further comparison is with the infamous battery additive controversy in the USA in the $1950 \mathrm{~s}^{9}$ (Note 5). A scientist from the National Bureau of Standards, publishing test results showing that the additive did not prolong the life of the battery, was criticized because customers using the additive judged differently. He was actally hounded, and lost his job (for a time), because the manufacturer of the additive was able to mobilize support for his case under the slogan "How can thousands of hardheaded businessmen be wrong?" Indeed, they could.

Similarly, thousands of hard-headed scientists can be wrong, and one scientometrician can be right. Provided, of course, he can justify his results in terms of the steps he has taken and their intrinsic validation.

\section{Intrinsic validation}

The craft of scientometrics may not be as "hard" as that of scientific research in the National Bureau of Standards, but in the third phase of development of the field approaches and their value have crystallized out. This is also why representation-asmirroring is becoming less important. Newcomers to the field of scientometrics may continue to think in terms of measuring something which, somehow, exists out there. But it is the robustness of the product, the way it can stand criticism, which is what counts. Recognizability is but one dimension, and it is especially the kind of work that has gone into the creation of the result which determines robustness.

Thus, intrinsic validation is now a real possibility. Basically, each of the three steps involved in the scientometrician's art are to be assessed in terms of their quality.

The quality of the building blocks that the scientometrician. is able to carve out depends on what is happening in the world that he is tracing. If peer review of manuscripts submitted to scientific journals is haphazard, publication of an article need not imply a positive assessment of quality of the work. If citation practices are undisciplined, the analysis of citations becomes risky, and the idea that handling large 
numbers of citations will average out any biases is an act of faith rather than a demonstrable argument. As I emphasized before, scientometricians depend on the scientific world for the quality of the data they can obtain. One of their tasks, I now add, is then to check the quality of the processes obtaining in science.

This is an important point to make, and it is not different from the situation of social science in general. The danger of neglecting such a check is often illustrated by the sociologist Durkheim's analysis of suicides in France in relation to a presumed higher degree of anomie in cities compared with the countryside. His data was based on official statistics and these were biased already in relation to anomie, because the pressure in the countryside to have a death not registered as suicide was higher than in the city. Official statistics reflect how social life is institutionalized, so do not provide independent data on its causes.

To check on the nature and quality of the processes in science (for example, peer review) is an essentially qualitative task. But it is part of the scientometrician's job, and it becomes even more important when one wants to study not-yet institutionalized situations and processes (see Section 5).

The quality of the second step, aggregation in the limited sense, resides, firstly, in the traceability of the analysis, and secondly, in the relevance of the final aggregation to the purpose at hand. Traceability is not just a matter of specifying what one does, there is also an element of justification. An example is the debate on so-called static journal categories versus dynamic journal categories, where not only the choices, but the effects of the different choices had to be traced. ${ }^{10,11}$ (This debate is also interesting for the third step, because Irvin and Martin had used static journal categories to present, in Nature, what they called the "decline" of British science, ${ }^{12,13}$ (Note 6). It is exactly because of their use of this caption that their analysis was applauded and criticized.)

The issue of traceability is complicated by the fact that relational analysis, based on linkages between items, can indeed be traced back to the individual items, while positional analysis creates maps, for example of structurally equivalent items which are not themselves linked. Aggregation (in the limited sense) then merges into point representation (Note 7).

Relevance to the purpose at hand is a broad formulation of the general methodological point that one's method should be adequate to the knowledge claims to be made eventually. I am using the broader formulation because scientometrics often serves other audiences than the own scholarly community, so its products are broader than knowledge claims aimed at colleagues/competitors. To check relevance one should understand what is happening in the scientometrician's work, not only be able to report on the steps in the data analysis. 
Take for example co-citation and co-word maps. The building blocks for co-citation maps are citations (themselves heterogeneous), and these are put together according to algorithms which create clusters which represent only part of the field (in the sense that less than $50 \%$ of the citing articles is connected to a cluster). In order to assess the quality of such maps, one can discuss the methodology, but one also has to look at the nature of the building blocks and recognize that referencing is persuasion, ${ }^{14}$ or better, citations function as legitimations of author's accounts. Citing draws on legitimatory repertoires, and the co-citation clusters select from these repertoires the currently popular key papers. This qualitative analysis of aggregation into co-citation maps indicates how these are suitable for explanatory purposes, comparable with the way a senior scientist will guide a novice in the area to the key papers to read, but do not reflect research dynamics.

With co-word analysis, the building blocks and the aggregation step are different. Scientific articles contain words with topical power (they flag a topic, link up with other topics, indicate pathways, force readers). After such words have been carved out, they are aggregated into maps by selecting for co-occurrence and tracing linkages and densities of linkage. The maps show pathways rather than clusters, and can be difficult to understand. A similar kind of aggregation would occur naturally when research group leaders would report on the state of the field and ongoing and future work of their groups in relation to it. Co-word maps are thus suitable to purposes of tracing connections and locating work strategically (Note 8 ).

Instead of comparing the two kinds of maps as competing representations of one and the same thing "out there", I have shown that they are suitable for different purposes. Valid use of one kind of map or another is then use for a purpose at hand for which they are indeed suitable.

Point representation, the third step, refers to (re)presenting one's construction to an audience. A key point about scientometrics is that their use of data bases enables them to produce their "stories" in large quantities (once the data base is available and the procedures have been set up) and without the direct help of scientists themselves. This is what makes scientometrics interesting: intellectually, because it allows analysis of actual and emerging collective levels, and practically, because third parties, like administrators and policy makers can get access to science without creating immediate dependence on scientists themselves.

This last point indicates that it is not only the methods per se that should be assessed as to quality, but also the socio-cognitive location of the scientometrician. In practice, this will often be the location, competences and reputation of a group or an institute working in the field. 
In all three steps, to achieve quality requires an assessment of situations and processes which is essentially qualitative (and often sociological). So there is a fourth aspect in ensuring robustness. Just like social scientists in general have a double task: doing their own job of aggregation well, and checking on naturally occurring processes, scientometricians, in spite of their avowed focus on so-called quantitative approaches, have a qualitative task as well if they want to say something sensible about science, not just play with the data they found laying around. One part of this qualitative task is to check on the nature and quality of the building blocks that the scientometrician can and will use, and on the possibility of working with building blocks at all.

\section{Studying not-yet-codified situations and processes}

My fourth requirement of quality, an assessment of the situation of the object of the scientometric study, leads to a set of new questions: what can a scientometrician do if his or her assessment of the situation shows that there is insufficient institutionalisation (and attendant quality control) to carve out building blocks and use them for aggregation?

Consider peer review and the use of publications as building blocks. The quality of these building blocks depends on the quality of the evaluative repertoire that has evolved in the research area or discipline. In physics and (neo-classical) economics, for example, very reliable assessments can be made because specific approaches have been articulated and agreed. Biomedical sciences, with their larger task uncertainties, show more dissensus (about techniques as well as about knowledge claims). ${ }^{16}$ In some disciplines in the humanities, individual appreciation is dominant.

There may also be situations where there is no evaluative repertoire at all, and the whole concept of 'peer' loses its meaning. In newly evolving fields, or in fragmented fields, there is insufficient cosmopolitan interaction to build up a shared evaluative repertoire. So scientometricians studying such an area cannot use publications as reliable building blocks for their aggregation. There are no codes (in the broad sense) and institutionalized patterns to draw upon.

Emerging or changing situations are "hot" and more difficult to trace by scientometrics than "cold" institutionalized situations. The dichotomy cold/hot is not, of course, a simple one; there are many "lukewarm" situations. But the distinction is useful to articulate the question what scientometrics can do, once one accepts that there is a qualitative part to its task.

If newly developing research areas which are not very well reflected in scientific journals, and perhaps not even in citing practices, are difficult to trace with present 
scientometric methods, is this something to resign oneself to, saying that there are some things scientometrics just cannot do? Or is it an occasion to try and extend the scientometrician's craft? (Note 9). Clearly, emerging phenomena and non-textualized phenomena do not lend themselves easily to scientometric analysis. If there are no building blocks, most often because actors do not yet create products/expressions in the form of building blocks for the new purposes, the scientometrician's craft cannot work.

But there are reasons not to resign oneself to this situation. For one thing, "hot" situations are just as much part of science as "cold" situations. For another, there is increasing interest in what happens at the interface between science and society: patents and links with technology more generally; non-academic impact of scientific research. While some of these interface phenomena have become institutionalized and somewhat codified, they are not always textualized. And even if they are, the texts are heterogeneous, and thus difficult to collect and analyse.

This is one part of the story. The other part is that scientometricians cannot choose for themselves whether to step into these "hot" waters or not. With the advent of scientometrics and science indicators, the world has changed. Actors now expect a contribution from scientometrics, and will ask for indicators for whatever it is that concerns them. University-industry linkages are one example, and scientometric studies and attempts at indicator building have been done, based on collaborative articles, citations in patents, and the like. It is indicative that these studies focus on those parts that are texts, or have been transformed into text, in order to analyse a phenomenon which is itself not textual (and covers many more heterogeneous and informal texts and inscriptions than the scientometrician can and will use).

The focus on texts is perhaps a reasonable approximation for the core of science, at least for the "cold" core. For interface phenomena and "border crossings," however, a text-focussed approach introduces asymmetry, because it has to start from the textual core and go outward. ${ }^{18}$ Some interactions will then remain invisible, unless special data collection is undertaken. Cees le Pair's point about the invisible technologist is relevant here; for the case of electron microscopes, he has been able to do special data collection, based on his understanding of the situation, and to show impacts not visible in the usual analyses (e.g., Ref. 19).

Thus, instead of resigning itself, scientometrics is already analyzing emerging, heterogeneous and little textualized situations. It does this with a mixture of first-phase (try out whatever you can find) and third phase approaches (analyse the dynamics of the situation in order to find the right building blocks and understand the validity of your results). 
These activities (partly enforced, partly on own initiative) raise a further question, which I will formulate with the help of another example. Recently, interest in nonacademic impact of research (as it is now called in the UK), or in societal quality of research (as it is now called in the Netherlands) has surged. The issue is important enough, but it is only partially understood, because knowledge transfer and knowledge dissemination studies have worked with too limited frames of analysis. I have been involved in exercises where science organisations (research institutes, universities, research council bodies) felt themselves forced to do something about measuring nonacademic impact, thought of indicators and drew up lists, running from academics being required to specify their dissemination activities to paying an agency to collect press cuttings. In other words, they reverted to approaches belonging to the first phase of the evolution of scientometrics.

The third-phase approach, instead, would be to understand the situation and the dynamics before starting with indicators, and only then derive (or just be on the look out for) possibilities to "tap" data, or induce processes that allow "tapping." I will develop this a bit further to show what is possible.

When relevance of research is recognized, and becomes one of the criteria for funding and other support, it can be transformed into resources for further research and into reputation. In this way 'credibility cycles' emerge which include relevance and utility of research. ${ }^{20,21}$ For example, in parts of chemistry and in the engineering sciences, a viable combination of scientific and societal quality has emerged where academic research is "relevant" (the quotes indicate that the relevance is indirect - an example would be when studies of model substances are used to complement research on industrially used materials), and users and sponsors are knowledgeable. In such areas, peer review also considers technical and industrial relevance, there are substantial collaborative ties, and joint products (not always in the form of publications). And there is a guarantee of quality. The cycles of transformation in these fields thus include assessments and choices, and therefore provide items (competent activities, texts) that can be used as building blocks in scientometric analyses.

In such cases, an epistemic community has emerged, of hybrid composition, sustaining cognitive interaction and cumulation of work, agenda building and evaluative repertoires. Intermediaries between research and its potential relevance on the one hand, and user communities/contexts and society more generally on the other hand, are not ad hoc anymore, but part of an institutionalized practice. So there is codification, although not always centred on publications or other texts. And the institutionalized practices can be drawn upon for building blocks, and for expertise. 
In other areas, such institutionalized practices do not obtain, or only partially. In some areas of social and behavioural sciences, for example, like organisation studies and test psychology, there are strong and cognitively structured ties with clients and customers. The production of text is not focussed on scholarly articles, but on advice, design, and test results. In other areas of social science, there is a strong dependence on government bodies as commissioners and audiences of research. And there are areas without any such institutionalized linkages.

Similar remarks can be made for other disciplines. The implication is that one should diagnose the situation in terms of codification of linkages and textual residues, before one does anything about indicators.

What if there is little or no institutionalization of interactions with society? One can still experiment with indicators, but should focus on processes rather than outcomes, and exploit opportunities to learn about the situation and the dynamics. One possibility is to focus on intermediaries between the research and societal uptake and impact. Their existence and their functioning are themselves qualitative indicators of linkages between science and society. Case studies of interactions and impacts are important as a preliminary to indicator exercises, especially because the links between research and impact are indirect. Thirdly, if indicators are to be used, it should be in an experimental mode, and be parallelled by qualitative studies of what is happening.

\section{Induced aggregation}

In the fluid situations discussed in Section 5, the construction and use of indicators may well shift ongoing processes in a certain direction. If a research council decides to use press clippings as an indicator of relevance, scientists will shift their credibility cycle and work to get noticed in the press. If a scientometrician is hired to develop indicators for a science organisation, he or she has a responsibility to educate this organisation about the possibilities and limitations of indicators, trying to avoid mistakes that belong to an earlier phase of the field of scientometrics. Such a role is well recognized in the recurrent warning not to use bibliometric indicators to judge performance of individuals. In not-yet-codified situations it is less clear-cut what the content of the "education" should be, but the responsibility is still there.

The key phenomenon to consider is 'induced aggregation': a change in natural aggregation activities induced by pro-active use of (science) indicators. There are always external forces shaping aggregation, but when these are linked to the introduction and use of science indicators, it becomes something that concerns scientometricians. 
Induced aggregation is widespread. When scientists depend on the patronage of an organisation (a university or a research council) that asks for indicators, the chances are that they will move to improve their score on whatever indicators the organisation, in its wisdom, has settled on. Additional aggregation activities are induced, and become institutionalized. Publishing is now part of the academic's job, instead of a free choice, and the insistence of universities and other organisations on impressive publication lists has evoked strategic responses, where academics think and work in terms of 'least publishable units. ${ }^{22}$ Similarly, dissemination along indicator-induced lines may in time become part of his or her job.

The aggregation that is induced may not be desirable; the practice of working toward 'least publishable units' is generally condemned. The desirability of such induced practices is not just a practical question, to be debated and resolved by the actors. If the practices are induced by new indicators, it is also a responsibility of scientometricians. The question then is not just about the quality of the indicators as such, but also, and primarily, about their role as incentives for induced aggregation.

Scientometricians thus have a role to play. They are asked to come in by administrators and policy makers, who most often want quick solutions, even if the building blocks for indicators are absent. Then, scientometricians must mobilise their secondary, qualitative craft to help actors build up practices in which reliable building blocks are produced. In addition, they should reflect on the direction of the evolving aggregation processes, and perhaps take science, rather than science policy as their frame of reference.

Have science indicators already induced modified forms of aggregation in the workings of science? In my view, science indicators have followed changes, rather than leading them. Publish-or-perish, as an imperative, relates to professional career structures in the USA, and to reputational strategies derived from the dominance of the USA in world science (this is very visible in the biomedical sciences in the 1960s, so before the rise of scientometrics). In the 1970s, the strategic games that scientists were playing among themselves, especially for the allocation of resources within institutions, became easier to play with the increasing availability of the Science Citation Index. Existing patterns were enhanced, but not changed.

In the case of scientific activities linking up with wider society, in areas where there is as yet little institutionalization, however, there may well be an effect. In fluid situations, what would be a minor factor otherways can determine the path that is followed. The example how the QWERTY keyboard became dominant, often quoted in economics and sociology of technology, is instructive in this respect. ${ }^{23}$ 
In a study of collaboration between universities and industry in the framework of R\&D programmes of the European Union, one interesting finding was that the extent of collaboration had not changed very much, but it was now more institutionalized and made visible. ${ }^{24}$ Actors followed a new rule: You should not only collaborate, but be seen to collaborate. This is induced aggregation through new policy, and it is modulated further by the sort of indicators that are used. In less institutionalized areas, like nonacademic linkages of social sciences, the use of indicators may come first, and their modulating effect might set a pattern in emerging institutionalization, rather than following it.

Thus, induced aggregation occurs, and induced aggregation driven by indicators made possible by scientometrics is a real possibility. This implies that scientometrics contributes to (or interferes with) the evolution of science, rather than just reflecting it. The contribution is not limited to the institutional aspects, where policy makers and administrators are enabled to know more about science. There is a cognitive aspect as well, in the sense that science can become more reflective when it can avail itself of the products of scientometricians.

\section{Reflections}

Without robust building blocks, linked to ongoing scientific practices, there is no scientometrics, only number crunching. By now, scientometrics has such building blocks, but I would hesitate to call it a fully mature field.

What I have shown in this article is that one can analyze the sociocognitive conditions for scientometrics. Recognition of these conditions, and a secondary and qualitative scientometrician's craft building on it, are necessary for maturity.

Scientometrics has achieved such maturity partially, at best. This has to do with the path it has followed historically, starting with data looking for something to indicate. Thus, the focus has been on patterns in the outcomes, rather than on the processes of science. Derek Price's Citation Cycle, and his theories of growth of science "at the surface" are major achievements, but they are about outcomes, and about outcomes of a particular kind of science, where knowledge production has been institutionalized, and in such a way that texts are regularly produced, and under quality control of comcolleagues. Other types of knowledge production, with other types of quality control (cf. engineering sciences, social sciences) do not figure in this picture.

Scientometrics has difficulties with "hot" fields, and with phenomena based on informal interaction and production, or otherwise difficult to tap. The field of scientometrics has other difficulties. It works with a historically determined set of data 
bases, the ISI data bases being the most prominent. The bias involved when applying scientometric methods developed for these data bases to fields and topics with other practices and dynamics has often been noted and criticized. But too little has been done to remedy the situation. An alternative to ISI's Science Citation Index may not be feasible in the short term; the European Union might provide a framework to work towards an alternative, however.

This leads on the question of the influence of scientometrics on developments in science. I have discussed the phenomenon of induced aggregation and have given examples where the "inducing" was led by government bodies, research councils and university administrations. By now, policy makers and administrators ask for indicators immediately (also when these are not, or not yet, appropriate), and may thus "induce" strategic and possibly empty responses.

Just the availability of scientometric tools and analyses has effects as well. While there has been some "scientometrics push", most of the effects derive from the way scientists themselves (and administrators) exploit tools and analysis for their own purposes. Now that journal impact factors are available, the choice where to submit a paper, always guided by considerations of status of the journal, audience, and chance to be accepted, can also refer to the various impact factors. (This was originally stimulated by scientometricians using impact factors to rate performance - but the scientists needed little pushing.)

Through scientometrics, scientific activities are becoming more explicit and to some extent reflexive. Discussions become sharper because they refer to products like indicators and maps.

I would propose that scientometrics recognizes this possibility of contributing to science becoming more reflexive and accepting it as a responsibility, in addition to its traditional work of data mining and the creation of scientometric panopticums. New understanding of science is made possible by scientometrics, even if in practice, a lot of work is pedestrian and not up to this challenge. Or if it is, it may not reach practitioners of science; some of the work in scientometrics is hermetic.

Derek Price was extremely good in point-representing his scientometrics-based understanding of science to wider audiences. His two little books on Science Since Babylon and Little Science, Big Science were read by scientists and policy makers all over the world. So it is possible, for gifted individuals, to stimulate reflexivity through scientometrics. The challenge is to advance the craft of scientometrics itself so that the field contributes to this aim. Then, it would really become mature. 


\section{Notes}

1. Glänzel ${ }^{1}$ and the comments to this discussion paper in the same issue of the journal.

2. The phrase summarizes their position in the debates about their work in the early 1980 s. See Martin \& Irvin, ${ }^{2}$ especially p. 566.

3. My use of the metaphor of 'spying' can be supported by pointing out the importance of unobtrusive measures and routine collection of data.

4. The criticism of Irvine and Martin's study by one of their radio-astronomer subjects is an exemplary case. The second phase of scientometrics saw many such cases, but it is not just a question of maturity of a field. The practice of scientometrics will always be conducted in the same world as inhabited by those who will feel the effects of the results and think they have a right to judge their quality.

5. Ch. 4.Il, A Problem of Politics: The Battery Additive Controversy, pp. 196-208.

6. Irvine et al.'s ${ }^{12}$ positioning of their scientometric work has been kept up, cf. Martin. ${ }^{13}$

7. I owe this point to Loet Leydesdorff, in the discussions at the Workshop on "Quantitative Approaches to Science and Technology Studies" organized by the Network of European Centres in Science and Technology Studies (NECSTS), Amsterdam, 21-24 May 1996.

8. This analysis of co-citation and co-word analysis draws on Rip. ${ }^{15}$

9. Cases of rapid change have been traced scientometrically: White \& Sullivan, ${ }^{17}$ but this was a short period of change in an otherwise "cold" field and data could be found in 'Letters' journals.

\section{References}

1. W. GLÄNZEL, U. SCHOEPFLN, Little scientometrics, big scientometrics - and beyond, Scientometrics, 30 (1994) 375-384.

2. B. R. MARTIN, J. IRVINE, Evaluating the evaluators: A reply to our critics, Social Studies of Science, 15 (1985) 558-575.

3. A. RIP, Wetenschap als Mensenwerk, Ambo, Baam, 1978.

4. P. HEALEY, H. ROTHMAN, P.K. HOCH, An experiment in science mapping for research planning, Research Policy, 15 (1986) 233-251.

5. S. WOOLGAR, Beyond the citation debate: towards a sociology of measurement technologies and their use in science policy, Science and Public Policy, 18 (1991) No. 5, 319-326.

6. M. CALLON, J. LAW, A. RIP, Mapping the Dynamics of Science and Technology, Macmillan, London, 1986.

7. B. R. MARTIN, J. IRVINE, Assessing basic research: Some partial indicators, of scientific progress in radio astronomy, Research Policy, 12 (1983) 61-90.

8. 0. AMSTERDAMSKA, L. LEYDESDORFF, Citations: Indicators of significance?, Scientometrics, 15 (1989) 449-471.

9. J. L. Penick JR., C. W. Pursell JR., M. B. Sherwood, D. C. Swain, The Politics of American Science, 1939 to the Present (Revised Edition), MIT Press, Cambridge, Mass., 1972.

10. L. LEYDESDORFF, Problems with the 'measurement' of national scientific performance, Science-and Public Policy, 15 (1988) 149-152.

11. J. ANDERSON, P. M. D. COLLINS, J. IRVINE, P. A. ISARD, B. R. MARTIN, F. NARIN, K. STEVENS, On-line approaches to measuring national scientific output - A cautionary tale, Science and Public Policy, 15 (1988) 153-161.

12. J. IRVINE, B. MARTIN, T. PEACOCK, R. TURNER, Charting the decline of British science, Nature, 316 (1985) 587-590. 
13. B. R. MARTIN, British science in the 1980 s - Has the relative decline continued?, Scientometrics, 29 (1994) 27-57.

14. G. N. GILBERT, Referencing as persuasion, Social Studies of Science, 7 (1977) 113-122.

15. A. RIP, Mapping of science: Possibilities and limitations, in:-A. F. J. VAN RAAN (Ed.), Handbook of Quantitative Studies of Science and Technology, Elsevier Science Publishers, Amsterdam, 1988, p. 253-273.

16. R. WHItLEY, The Intellectual and Social Organisation of the Sciences, Oxford, Clarendon Press, 1984.

17. D. H. WHITE, D. SUllivaN, E. J. BARBONI, The interdependence theory and experiment in revolutionary science: The case of parity violation, Social Studies of Science, 9 (1979) 303-327.

18. A. J. NEDERHOF, R. F. MEIJER, Development of bibliometric indicators for utility of research to users in society: measurement of external knowledge transfer via publications in trade journals, Scientometrics, 32 (1995) $37-48$.

19. C. LE PAIR, The citation gap of applicable science, in: A. F. J. VAN RAAN, (Ed.), Handbook of Quantitative Studies of Science and Technology, Elsvier Science Publishers, Amsterdam, 1988, p. 537-553.

20. B. LATOUR, S. WOOLGAR, Laboratory Life, Sage, Beverly Hills, Cal.,1979.

21. A. RIP, The Republic of Science in the 1990s, Higher Education, 28 (1994) 3-23.

22. W. E. SNIZEK, Comment on Nicolini et al., Scientometrics, 32 (1995).117-120.

23. W. B. ARTHUR, Competing technologies, increasing returns and lock-in by historical events, Economic Journal, 99 (1989) 116-131.

24. M. DAHL, S. LAHLOU, Measurement of network effects from the EC Science/Stimulation Programmes, Scientometrics, 21 (1991) 325-342. 